\title{
CDISC SDTM Model Version 1.4
}

National Cancer Institute

\section{Source}

National Cancer Institute. CDISC SDTM Model Version 1.4. NCI Thesaurus. Code C161428.

The 1.4 version of the CDISC Study Data Tabulation Model (SDT M). 